Carlos Eduardo Siqueira ${ }^{1}$

Francisco Pedra ${ }^{2}$

Heleno Rodrigues Corrêa Filho ${ }^{3}$

Maria Maeno ${ }^{4}$

Hermano Albuquerque de Castro ${ }^{2}$

\section{A experiência do Observatório de Saúde do Trabalha- dor (Observatoriost) no Brasil}

\author{
The experience of the Worker's Health Observatory \\ (Observatoriost) in Brazil
}

${ }^{1}$ College of Public and Community Service. The Mauricio Gastón Institute for Latino Community Development and Public Policy. University of Massachusetts Boston, Boston, MA, United States of America.

${ }^{2}$ Centro de Estudos de Saúde do TrabaIhador e Ecologia Humana - Escola Nacional de Saúde Pública (Cesteh/ENSP), Fundação Oswaldo Cruz, Ministério da Saúde, Rio de Janeiro, RJ, Brasil.

3 Departamento de Saúde Coletiva, Faculdade de Ciências Médicas, Universidade Estadual de Campinas (Unicamp), Campinas, SP, Brasil.

${ }^{4}$ Fundação Jorge Duprat Figueiredo de Segurança e Medicina do Trabalho (Fundacentro), Ministério do Trabalho e Emprego, São Paulo, SP, Brasil.

Contato:

Carlos Eduardo Siqueira

E-mail:

carlos.siqueira@umb.edu

O Projeto Observatoriost (Rebrast) foi financiado pelo Fundo Nacional de Saúde, do Ministério da Saúde do Brasil, pelo processo $n^{\circ}$ 25388.000967/2009-61 através da Fiocruz, segundo Termo de Cooperação nº 109/2009, publicado no Diário Oficial da União de 18/12/2009, Seção 3, Número 147, p. 242.

Os autores declaram não haver conflitos de interesses.

Recebido: 20/02/2012

Revisado: 05/03/2013

Aprovado: 08/03/2013

\section{Resumo}

Antecedentes históricos apontam a mobilização sindical e de pesquisadores para criar um Observatório de Saúde do Trabalhador (OST) que permitisse oferecer informações com credibilidade e subsidiar a defesa da saúde. Este trabalho teve o objetivo de rever e analisar os antecedentes internacionais e brasileiros da mobilização de sindicatos, centros de estudos sindicais e intersindicais e pesquisadores de instituições do setor que criaram um observatório presencial e virtual para comunicação e repositório de informações científicas. Foram utilizados métodos de intervenção e observação participantes e levantamento documental. O relato parte de iniciativas de superação das políticas neoliberais. Tais iniciativas impulsionaram a criação do Observatoriost em 2010 e o mantiveram ativo até 2013 compilando documentos, relatos de imprensa e agendas sindicais. O observatório foi conduzido em cogestão com seis centrais sindicais por meio do Comitê Editorial das centrais que respeitou a diversidade e a autonomia dos atores envolvidos. A coordenação rotativa do portal pelo comitê evidenciou a maturidade política e sua articulação. Os principais desafios postos para a continuação da iniciativa foram de integrar e formar pesquisadores e profissionais comprometidos organicamente com os trabalhadores na luta pela defesa da vida e saúde.

Palavras-chave: observatórios de ciência e tecnologia; saúde do trabalhador; sindicatos; redes de informação em saúde do trabalhador; políticas públicas de saúde.

\begin{abstract}
Historical antecedents led labor organizations and worker's health researchers to create a Worker's Health Observatory aimed at disseminating credible information and subsidizing the defense of workers' health. This paper reviews and analyzes the national and international backgrounds that mobilized the labor unions, labor unions study centers, and workers' health researchers to produce a virtual and in person observatory aimed at communicating and storing scientific information. Participant observation and intervention, as well as document review methods were used. The paper starts by discussing the initiatives to overcome neoliberal policies. These iniciatives allowed the "Observatoriost" to be created in 2010 and kept in activity, compiling documents, press reports and labor union agendas, until 2013. The observatory was co-managed by six associations of labor unions (the so called "Centrais" in Brazil) through the Editorial Committee, which complied with the diversity and autonomy of the involved actors. The "Observatoriost" rotatory coordination established by the associations of labor unions Editorial Committee proved they were politically mature and prepared to networking. The main challenges for keeping this initiative were to prepare and integrate researchers and other professionals who would be organically committed to workers' struggle for life and health.
\end{abstract}

Keywords: science and technology observatories; occupational health; labor unions; occupational health information networks; public health policies. 


\section{Antecedentes}

Siqueira e Carvalho (2003) revisaram os objetivos de diversos observatórios existentes no início da década de 2000 ao pesquisar o termo "Observatório" na ferramenta de busca Google. Identificaram dois tipos principais, não excludentes: os que funcionam como uma rede e os que funcionam como um repositório virtual de informações (clearinghouse) em páginas de internet.

Baseando-se nesta revisão, os autores discutem o Observatório das Américas como uma rede de profissionais e organizações não governamentais (ONGs), incluindo universidades e organizações de defesa do trabalhador. Esse Observatório organizou, entre os anos 2000 e 2006, conferências no México, no Brasil e na Costa Rica para troca de experiências entre profissionais e líderes da área de saúde do trabalhador e ambiental. Como produto da conferência no Brasil, em 2002, foi publicado um número especial da revista Ciência \& Saúde Coletiva em 2003 (SIQUEIRA; CASTRO; ARAÚJO, 2003) intitulado "Integrando Saúde do Trabalhador e Saúde Ambiental: Observatório das Américas", que reuniu contribuições de pesquisadores e ativistas brasileiros e de outros países, como Estados Unidos, Peru e Venezuela. Esta rede diminuiu muito suas atividades depois de 2006, principalmente devido à falta de recursos financeiros.

A Área Técnica de Saúde do Trabalhador (Coordenação de Saúde do Trabalhador - Cosat $^{5}$ ) do Ministério da Saúde do Brasil criou, em 2003, o Observatório Nacional de Saúde do Trabalhador como clearinghouse hospedada na página web da Organização Pan-Americana da Saúde (OPAS), em Brasília. Essa página surgiu para propiciar amplo acesso a informações e análises sobre saúde do trabalhador, facilitar a produção de estudos e pesquisas, bem como a melhor formulação, acompanhamento e avaliação de políticas e projetos setoriais na área, contribuindo para o desenvolvimento do controle social na área de saúde do trabalhador. Apesar dessa página virtual ter desempenhado um papel importante na divulgação de materiais e documentos preparatórios da 3a Conferência Nacional de Saúde do Trabalhador, realizada em Brasília em novembro de 2005, o Observatório Nacional de Saúde do Trabalhador não se consolidou e a página saiu do ar após 2006.

Essas duas experiências e outras discussões sobre o assunto em alguns estados brasileiros expressaram a necessidade e o desejo comum de integrar atores sociais e informações técnicas para construir e avaliar políticas nacionais e estaduais de Saúde do Trabalhador, analisar o panorama epidemiológico das doenças e dos acidentes do trabalho no Brasil e promover amplo debate sobre programas e estratégias capazes de reduzir a morbimortalidade relacionada com o trabalho no país e nas Américas.

Embora o propósito de muitos que contribuíram para essas duas iniciativas fosse criar Observatórios de Saúde do Trabalhador (OSTs) que incluíssem lideranças de sindicatos, federações ou centrais sindicais, obteve-se pouco sucesso. Parte da razão para essa pequena participação se deve às políticas neoliberais implantadas no país na década de 1990, que provocaram o acirramento dos graves problemas de desemprego, a precarização do trabalho e a tercerização, a redução da renda dos trabalhadores, a desnacionalização da economia, a elevação das taxas de juros a patamares recordes no mundo e a consequente desproteção da força de trabalho, o que levou o movimento sindical brasileiro a concentrar sua energia no enfrentamento dos determinantes macros da saúde (HARVEY, 1989; SIQUEIRA; CASTRO; ARAÚJO, 2003; HARVEY, 2005; BOITO; GALVÃO; MARCELINO, 2009).

Neste cenário, a implantação da participação direta de representações sindicais na formulação de políticas públicas em Saúde do Trabalhador foi determinada por leis formuladas no modo chamado "participação pelo alto", principalmente nos conselhos e nas comissões de nível nacional, onde ocorreria um divórcio de origem entre a formulação das leis e da estrutura do Sistema Único de Saúde (SUS) e as práticas sindicais e locais que iriam instituir a Saúde do Trabalhador (LACAZ, 1994; PINA; CASTRO; ANDREAZZI, 2006).

A construção da participação social direta dos representantes dos trabalhadores nos níveis locais, regionais e estaduais não foi absorvida pelo movimento sindical, deixando isolado o movimento pela reforma sanitária dos anos 1980 e 1990 conduzido principalmente por técnicos, gestores e pesquisadores da saúde coletiva brasileira. Isso não impediu o avanço das políticas públicas, que formularam a abertura formal e legal para a participação direta dos representantes dos trabalhadores, sujeita a confrontos relacionados aos limites que teriam as resoluções das Conferências Nacionais de Saúde e de Saúde do Trabalhador quanto ao seu caráter deliberativo ou "meramente consultivo" (DIAS; HOEFEL, 2005; CONSELHO NACIONAL DE SECRETÁRIOS MUNCIPAIS DE SAÚDE, 2011).

Na ausência de reivindicações diretas da maioria dos sindicatos pela cobertura universal e pela presteza no atendimento aos usuários pelo sistema público

\footnotetext{
${ }^{5}$ A Cosat tinha a atribuição de coordenar as ações na área em âmbito ministerial no Brasil e foi substituída posteriormente pela Coordenação Geral de Saúde do Trabalhador (CGSAT).
} 
de saúde, os trabalhadores focalizaram suas reivindicações nas relações com o sistema privado de forma predominante, o que foi objeto de várias tentativas de reorientação pelos movimentos sindical e sanitário no Brasil (PIMENTA; CAPISTRANO-FILHO, 1988; PINA; CASTRO; ANDREAZZI, 2006).

O Ministério da Saúde do Brasil apoiou paralelamente, entre 2000 e 2011, a instituição de portais de internet com capacidade de subsidiar políticas públicas em saúde que abrangiam a Saúde do Trabalhador na tentativa de se influenciar a gestão de políticas públicas de promoção e atenção à saúde. Por iniciativa do Ministério da Saúde, a partir de 2003, foram criados a Rede Nacional de Atenção Integrada à Saúde do Trabalhador (Renast), 190 Centros de Referência de Saúde do Trabalhador (Cerests) até 2011, e uma rede de serviços de municípios-sentinela cuja finalidade é a disseminação de ações de atenção integral à saúde do trabalhador pelo SUS. Os Cerests foram concebidos como nível secundário de atenção e forte caráter formador e disseminador de ações de assistência e vigilância (BRASIL, 2006).

A partir de 2005, cresceram bastante as lutas reivindicativas e as greves dos trabalhadores em diversos estados (BOITO; GALVÃO; MARCELINO, 2009). Um elemento importante neste processo foi o desenvolvimento contínuo da unidade entre as seis centrais sindicais, apesar de históricas diferenças políticas e ideológicas: a Central Única dos Trabalhadores (CUT), a Força Sindical, a Nova Central Sindical de Trabalhadores (NCST), a Central Geral de Trabalhadores do Brasil (CGTB), a Central de Trabalhadores e Trabalhadoras do Brasil (CTB) e a União Geral dos Trabalhadores (UGT). Essa unidade em várias frentes de luta foi facilitada pela legalização dessas centrais sindicais, objetivo perseguido há quase cem anos pelos trabalhadores e sistematicamente reprimido pelas elites, o que assegurou a organização legal, financeira e institucional dos trabalhadores em âmbito nacional (SOARES, 1985).

A ideia de um OST foi retomada em 2008, a partir da percepção desse novo momento no movimento sindical, reforçado pela legalização das centrais sindicais, e do diagnóstico de que havia necessidade de coesão política e agenda comum em Saúde do Trabalhador entre as lideranças sindicais organizadas nas centrais e de ação coordenada com técnicos do meio acadêmico-institucional, além daqueles atuantes nos serviços de saúde. Os formuladores do projeto inicial, pesquisadores do Centro de Estudos de Saúde do Trabalhador e Ecologia Humana (Cesteh) da Escola Nacional de Saúde Pública Sérgio Arouca (ENSP) da Fundação Oswaldo Cruz (Fiocruz), da Faculdade de Ciências Médicas da Universidade Estadual de Campinas (FCM/Unicamp) e da Universidade de Massachusetts Lowell, entendiam que havia necessidade de discussão interna entre as centrais para unificar reivindicações e políticas públicas na área de Saúde do Trabalhador em nível nacional, passo fundamental para tornar os trabalhadores protagonistas destas políticas públicas. Tinham claro que uma das lacunas nas ações em Saúde do Trabalhador era a falta de articulação entre as organizações sindicais, representantes dos trabalhadores, além de técnicos e pessoas que faziam parte da máquina do Estado (BRASIL, 2006).

Este conjunto de questões iluminou o desenho do projeto intitulado "Rede Brasileira de Saúde, Trabalho e Ambiente", apresentado em 2008 pelo Cesteh/ Fiocruz à Cosat, situada então na Diretoria de Saúde Ambiental e Saúde do Trabalhador da Secretaria de Assistência à Saúde (SAS) do Ministério da Saúde. O projeto foi aprovado em 2009 e recebeu financiamento por dois anos.

Este trabalho teve o objetivo de rever e analisar os antecedentes internacionais e brasileiros da mobilização de sindicatos, centros de estudos sindicais e intersindicais e pesquisadores de instituições do setor que criaram um observatório presencial e virtual para comunicação e repositório de informações científicas.

\section{Método}

Este relato foi construído a partir de relatórios elaborados e apresentados pelo Cesteh/Fiocruz ao Ministério da Saúde durante a execução do projeto "Rede Brasileira de Saúde, Trabalho e Ambiente (Rebrast)", além de material sobre o projeto publicado nas páginas do Portal do Observatório de Saúde do Trabalhador ${ }^{6}$. Os relatórios descrevem em linhas gerais as discussões e as decisões que ocorreram nos dois seminários entre as centrais sindicais promovidos pelo projeto. Os autores resumiram os principais temas que identificaram como importantes para disseminação neste relato, cientes de que os relatórios abrangem grande variedade de assuntos e temas abordados nos seminários. Por exemplo, a agenda política do Observatório ${ }^{7}$ foi discutida em grupo, nos dois seminários, entre dezenas de líderes sindicais e profissionais da área de Saúde do Trabalhador que atuam em diversos estados do país.

\footnotetext{
${ }^{6}$ www.observatoriost.com.br

${ }^{7}$ Por questões de espaço e pelo escopo deste relato, optamos por não detalhar aqui as discussões sobre a Política Nacional de Saúde do TrabaIhador, considerando que esta questão já tem sido abordada em outras publicações.
} 
A estrutura deste relato segue o planejamento do projeto, que foi desenhado como projeto participativo e democrático para construção de uma rede de profissionais e líderes sindicais e cujas decisões foram influenciadas ao longo do tempo pela participação deles nos dois seminários. A linha condutora do projeto, e também deste relato, baseou-se nos seminários e nos desdobramentos para a criação da rede através do Portal do Observatório.

Como o planejamento descrito das ações do Observatório foi participativo, os técnicos não organizaram a priori o que era domínio e iniciativa das lideranças sindicais, como os objetivos gerais e o conteúdo das ações. O planejamento acadêmico do Observatório se restringiu ao método que foi aceito e validado de maneira consensual pelo Fórum das Centrais.

\section{O Observatório de Saúde do Trabalhador (Observatoriost)}

O projeto tinha como objetivo inicial auxiliar a articulação de uma rede composta por organizações sindicais, em particular as centrais sindicais e os sindicatos a elas filiadas, profissionais de serviços e pesquisadores da área de Saúde do Trabalhador e representantes do Estado, principalmente do Ministério da Saúde, o que facilitaria as ações em Saúde do Trabalhador conduzidas pelo Estado ${ }^{8}$ coladas às necessidades apontadas pelo movimento sindical. Propunha também desenvolver um portal na internet como ferramenta para facilitar e dinamizar as ações de Vigilância em Saúde do Trabalhador, servir de biblioteca virtual de documentos e publicações na área de Saúde do Trabalhador e dar visibilidade aos diferentes sítios de internet das centrais sindicais, dos sindicatos, das associações de trabalhadores e vítimas de doenças e acidentes do trabalho. Para estruturar conceitualmente, elaborar o formato, a agenda política e implementar a rede, foram planejados dois seminários nacionais. O Cesteh foi a instituição responsável por coordenar o projeto e dirigir a construção do Observatório em parceria com o movimento sindical.

\section{Primeiro Seminário Nacional do Observatoriost}

Após processo de consulta prévia a todas as centrais sindicais, foi realizado o Primeiro Seminário Nacional do Observatoriost na Escola Nacional de Saúde Pública no Rio de Janeiro nos dias 23 e 24 de junho de 2009. Participaram representantes das seis centrais sindicais, da Cosat e pesquisadores da Fio- cruz, da Unicamp, da Faculdade de Saúde Pública da Universidade de São Paulo (USP), da Faculdade de Medicina de Botucatu da Unesp, entre outros convidados. A agenda do evento incluiu apresentações sobre as diferentes definições e os desafios conceituais e estruturais da saúde do trabalhador, o perfil epidemiológico das mortes no trabalho no Brasil, um protótipo de portal para o Observatoriost, além de discussões em grupo orientadas por roteiro que demandava respostas para uma série de detalhes a respeito do funcionamento do portal e da rede, formalmente intitulada Rede Brasileira de Saúde, Trabalho e Ambiente (Rebrast). Este primeiro seminário propiciou auscultar lideranças das centrais sindicais e representantes de sindicatos a elas filiados sobre a organização do portal e da rede, que passou, a partir dessa oficina, a ser chamada de Observatório de Saúde do Trabalhador.

Como resultado das deliberações dos grupos, sugeriram-se nomes e endereços eletrônicos, bem como a estrutura organizativa para a tomada de decisões sobre o conteúdo do portal. Os participantes confirmaram e enriqueceram o diagnóstico feito no desenho do projeto. Houve unanimidade sobre a necessidade de fortalecer os laços entre líderes sindicais, profissionais da área de saúde do trabalhador e áreas governamentais, e sobre a utilidade de se construir o Observatório. Além disso, todas as lideranças sindicais presentes afirmaram que o movimento sindical tem poucas divergências na área de saúde do trabalhador, fato que facilitaria atividades comuns entre todas as centrais sindicais. Decidiu-se constituir um Conselho Editorial para gerenciar o portal, composto por dois representantes de cada central e dois representantes dos pesquisadores ou técnicos da área de Saúde do Trabalhador. Este Conselho estaria encarregado de administrar e autorizar a publicação de informações e lidar com todas as questões relacionadas com o funcionamento do portal.

Após esse primeiro evento, uma empresa de informática foi contratada para formatar a página web no endereço www.observatoriost.com.br e várias articulações entre centrais sindicais e profissionais da área de saúde do trabalhador ligados ao Observatório foram desenvolvidas visando a contribuir para a discussão de pautas concretas que demandavam respostas das centrais sindicais.

Uma destas pautas contemplou o Nexo Técnico Epidemiológico Previdenciário - NTEp (BRASIL, 2007; OLIVEIRA, 2010), que sofreu ataques de representantes da Confederação Nacional da Indústria (CNI) visando a impedir a sua implan-

${ }^{8}$ Ver Pisast: Painel de informações em Saúde Ambiental e Saúde do Trabalhador. Disponível em: < http://pisast.saude.gov.br/forum/index.php> . Acesso em: 2 jul. 2013. 
tação (CONFEDERAÇÃO NACIONAL DA INDÚSTRIA, 2009). Tratava-se de resistir a mudanças de critérios de avaliação das condições de trabalho, com repercussões sobre a contribuição financeira das empresas ao Seguro de Acidente do Trabalho (SAT). No processo de aprofundamento da compreensão sobre este tema, representantes das centrais começaram a reunir-se com frequência no esforço de chegarem a uma posição consensual sobre o assunto e desencadearem ações em defesa dos aspectos que representassem avanços na defesa da saúde dos trabalhadores. Um importante seminário na Fundação Jorge Duprat Figueiredo de Segurança e Medicina do Trabalho (Fundacentro) em dezembro de 2009, com participação de lideranças sindicais, técnicos do setor público e privado e representantes da Organização Internacional do Trabalho (OIT) e da OPAS evidenciou a complexidade dos interesses dos diversos setores sociais e das dificuldades e obstáculos para implementar procedimentos que visam à construção de um sistema que propicie maior intervenção do estado na melhoria das condições de trabalho (NEXO TÉCNICO EPIDEMIOLÓGICO E FATOR ACIDENTÁRIO DE PREVENÇÃO, 2009).

Seguiram-se várias videoconferências nacionais com membros da coordenação do Observatoriost em diferentes estados do Brasil para discutir encaminhamentos concretos decididos no seminário e para programar atividades conjuntas das centrais na área de saúde do trabalhador, como as manifestações por ocasião do dia 28 de abril, Dia Mundial em Memória das Vítimas de Acidentes do Trabalho, nos anos de 2009 a 2011.

\section{Segundo Seminário Nacional do Observatoriost}

O segundo seminário nacional que lançou oficialmente o Observatoriost ocorreu no auditório da Força Sindical em 19 e 20 de maio de 2010 em São Paulo. Este seminário contou com a participação de cerca de cem pessoas, entre as quais representantes das seis centrais sindicais, da Cosat, do Ministério da Saúde, de profissionais de Cerests, do Ministério do Trabalho e Emprego, da Fundacentro, da OPAS, da OIT, da Confederação Nacional dos Trabalhadores na Agricultura (Contag) e de pesquisadores da Fiocruz, da Unicamp, da Faculdade de Saúde Pública da USP, da Faculdade de Medicina da Unesp-Botucatu, entre outros convidados. A agenda do seminário incluiu apresentação do portal do Observatório, de experiências internacionais em saúde do trabalhador e discussões em grupo sobre a agenda e o programa de trabalho cumpridos pelo Observatoriost nos anos 2009 e 2010.
Este seminário contou com cobertura do Canal Saúde da Fiocruz cujos repórteres entrevistaram líderes sindicais e acadêmicos acerca da magnitude dos acidentes e dos óbitos relacionados com o trabalho no Brasil, das políticas públicas necessárias para reduzi-los e da importância do protagonismo dos sindicatos e dos trabalhadores na melhoria da saúde do trabalhador brasileiro. As principais questões debatidas no seminário foram o detalhamento do portal e a agenda de trabalho do Observatório, abordados tanto nos grupos de discussão, como na plenária final. A mais importante definição acordada durante este evento foi a priorização da vigilância e prevenção das mortes no trabalho como eixo temático central para desenvolver o Observatório, porque se trata de problema grave no Brasil e seria tema prioritário para construir ações concretas e unitárias do movimento sindical na área de Saúde do Trabalhador.

\section{O portal Observatório Saúde dos Trabalhadores}

A partir do feedback do seminário, a página e o gerenciamento do portal do Observatoriost foram desenhados para dar conta dos seguintes elementos:

- Compilação de documentos, artigos e relatórios sobre saúde do trabalhador, enfocando particularmente: mortes e lesões no trabalho; vigilância epidemiológica da saúde do trabalhador; NTEp e Fator Acidentário de Prevenção (FAP); e atenção integral à saúde do trabalhador.

- Cobertura da grande imprensa e da imprensa especializada sobre saúde do trabalhador, incluindo notícias de jornal, fotos e vídeos de seminários organizados pelo OST, pelas centrais e pelos sindicatos afiliados, e órgãos do governo. Além disso, foram também publicados podcasts de entrevistas com lideranças sindicais e palestras proferidas por profissionais vinculados ao OST e ao Ministério da Saúde.

- Anúncios regulares de eventos patrocinados pelas centrais e por sindicatos afiliados, órgãos tripartites e demais instituições envolvidas na área de Saúde do Trabalhador, como o Tribunal Superior do Trabalho (TST). Por exemplo, o portal anuncia livros e eventos relacionados à área.

- Fórum interno para discussão e debate entre dirigentes das centrais e do Comitê Editorial, acessível através de senha.

- Cadastro de membros do portal para que estes pudessem receber boletim periódico com informações sobre os últimos assuntos publicados no portal. 
- Atualização constante do portal por membros do Comitê Editorial. No segundo semestre de 2011, o OST contratou jornalista com experiência sindical para facilitar a publicação de materiais e notícias.

- Contratação de empresa de informática para gerenciar o portal (webmaster) com regularidade e transformar o portal em Organização Social com a extensão de sigla de internet “.org”.

\section{Fórum das Centrais Sindicais em Saúde do Trabalhador}

O amadurecimento do trabalho conjunto das centrais no âmbito do Observatório, e paralelamente a ele, levou, em 2009, à decisão de convidar participantes do Observatoriost para reuniões do Fórum das Centrais Sindicais em Saúde do Trabalhador. O objetivo foi facilitar e fortalecer o debate entre as centrais, visando chegar a posições sólidas e unitárias em temas de saúde do trabalhador, incluindo a construção da unidade política das centrais em diversos fóruns de saúde do trabalhador, entre eles os de caráter tripartite. Por exemplo, as centrais tiveram uma série de encontros, entre 2008 e 2009, com a Agência Nacional de Saúde Suplementar (ANS) para discutir a cobertura oferecida aos sindicatos pelos planos privados de assistência médica suplementar. Estes encontros forjaram unidade entre elas na exigência de incluir a saúde do trabalhador nos contratos suplementares privados de saúde.

Após o seminário de maio de 2010, as centrais constituíram uma Secretaria Executiva rotativa, a cargo de cada central, por um período de seis meses, possibilitando a participação igualitária nas tarefas de coordenação deste fórum. A Secretaria Executiva ficou encarregada de convocar e garantir local e infraestrutura para reuniões regulares bimestrais e extraordinárias quando necessário, elaborar relatórios e encaminhamentos decididos pelos participantes, convidar outras instituições para as reuniões e apresentar proposta de calendário de reuniões.

A participação dos profissionais do OST no fórum das centrais solidificou a relação entre esses atores e grande parte dos temas de interesse passou a ser compartilhada com a concretização de convites das centrais sindicais para que os editores do Observatoriost comparecessem a reuniões convocadas pelo Fórum das Centrais, nas quais são discutidas pautas conjuntas do movimento sindical. Por diversas vezes, profissionais vinculados ao OST foram convidados a participar de congressos inter- nos das centrais como palestrantes sobre temas de saúde do trabalhador.

O apoio institucional do Ministério da Saúde para o OST facilitou o intercâmbio com os Cerests da Renast. O portal referencia diretamente os links institucionais vinculados com a rede dos Cerest. Os sindicalistas e os assessores técnicos do Observatoriost têm participado ativamente como convidados nas ocasiões anuais em que a rede se reúne para planejamento e avaliação nacional de cobertura, qualidade e propósitos dos serviços. A integração do OST com a rede dos Cerest constitui importante fator para o fortalecimento do vínculo com a rede de serviços de atenção à saúde do trabalhador relacionada ao SUS.

Oficina Nacional sobre Prevenção de Mortes por Acidentes no Trabalho

A priorização da vigilância e da prevenção das mortes no trabalho como tema principal do Observatoriost levou à organização de oficina em São Paulo, nos dias 11 e 12 de julho 2011, em parceria com o Fórum Análise e Prevenção de Acidentes do Trabalho ${ }^{9}$, liderado por professores da Faculdade de Saúde Pública da USP e da Faculdade de Medicina da Unesp-Botucatu. Essa oficina, realizada no Sindicato dos Bancários de São Paulo, Osasco e Região, contou com a participação de formuladores de políticas de saúde do trabalhador, profissionais da rede de serviços, de instituições governamentais, das centrais sindicais e de órgãos de pesquisa. Dentre seus objetivos, citam-se: a) obter síntese atualizada do panorama atual do problema dos acidentes de trabalho fatais, como descrever as tendências temporais, os setores prioritários e as experiências de intervenção; b) apresentar/recomendar textos para orientar a ação de serviços, sindicatos e pesquisadores diante dos casos de acidentes do trabalho fatais; c) elaborar recomendações de políticas públicas para enfrentar o problema; d) apresentar experiências bem-sucedidas de intervenção que reduziram mortes no trabalho.

Como preparação para a oficina, foi elaborado um termo de referência que reuniu contribuições de pesquisadores com reconhecida experiência em pesquisa e na implementação de programas de vigilância de acidentes de trabalho fatais. O termo de referência elencou os principais argumentos e estatísticas relativos à gravidade do problema e sugeriu políticas públicas necessárias para reduzir a magnitude e o impacto das mortes no trabalho.

${ }^{9}$ Fórum Acidentes de Trabalho: Análise, Prevenção e Aspectos Associados. Disponível em: <http://www.moodle.fmb.unesp.br/course/view. php?id=52>. Acesso em: 8 maio 2013. 


\section{O papel desempenhado por técnicos e centrais}

O desejo de construir uma aliança tão almejada entre o trabalho de lideranças sindicais com o de pesquisadores, professores e profissionais de órgãos públicos não tem sido acompanhado das devidas iniciativas que tornem essa prática natural e cotidiana. O OST aponta para a possibilidade de construção de aliança entre lideranças sindicais, pesquisadores, professores e profissionais de órgãos públicos com vistas a unir o conhecimento, a experiência e a prática dos diferentes atores interessados no enfrentamento das más condições de trabalho. Parece, no entanto, que o movimento sindical ainda não reconhece a importância do Observatoriost como sua prioridade.

Sintomático dessa situação é que até o início de 2012, o Fórum das Centrais não tinha resolvido a questão da ancoragem da página do portal Observatoriost. Desejava-se ancorar a página em uma organização social intersindical que pudesse veicular na internet uma página com características peculiares à extensão “.org”. As discussões foram encaminhadas para órgãos como o Departamento Intersindical de Estudos de Saúde e Ambientes do Trabalho (Diesat) e o Departamento Intersindical de Estudos Econômicos e Sociais (Dieese), e não estava afastada a hipótese dessa ancoragem institucional, mantidas as características de controle sindical rotativo organizado e compartilhado. Além disso, a sustentação financeira, ressalte-se, de pequenas proporções, não é um assunto equacionado e decidido nas centrais e tampouco em seu fórum.

Por um lado, os técnicos assumem a atribuição de informar devidamente os tópicos relevantes em saúde dos trabalhadores e ambiente, de propor discussões sobre temas polêmicos e, por outro, propõem-se a não interferir na tomada de decisões de encaminhamentos políticos e de gestão estratégica do movimento sindical. As decisões editoriais sempre foram tomadas por consenso, não havendo votação por maioria. A rejeição de qualquer tema ou proposta editorial por apenas um editor de qualquer das centrais foi suficiente para redirecionar o tema para discussões internas, de modo a não causar desgaste público ou das bases sindicais entre as categorias de trabalhadores.

Houve o cuidado de se preservar um espaço virtual e presencial exclusivo denominado "Fórum das Centrais”, no qual os técnicos só participaram quando convidados. Nesse espaço, os representantes das centrais sindicais se reuniram e decidiram em conjunto manter a perspectiva da ação coletiva segundo suas políticas específicas.

O papel atribuído pelo Fórum das Centrais aos técnicos foi de subsidiar de modo ético, sem subordinação política e sem conflitos de interesse, as discussões sindicais sobre o tema saúde, trabalho e ambiente. A participação de alguns profissionais na elaboração do projeto se deu a partir de seu compromisso profissional e acadêmico em construir este Observatório, sem que esta participação refletisse necessariamente a posição de suas instituições de origem. Os profissionais vinculados ao Cesteh, porém, tiveram apoio institucional e o representaram oficialmente. O balanço da participação, realizado pelos técnicos no Observatório, sugere que estes foram os mais compromissados com a criação e a manutenção do portal desde o seu início. Os seminários atraíram a presença de dezenas de técnicos de instituições governamentais, porém sem continuidade e com pouca ligação com o portal.

O papel dos representantes sindicais, também percebido pelo grupo técnico assessor, foi de ampliar seu debate para perspectivas acadêmicas e reunir instrumentos para suas ações coordenadas nos pontos em que conseguiram avanços e conquistas unificadoras entre os anos de 2004 e 2011, como foi o caso da defesa do NTEp, do FAP e da humanização do atendimento médico-pericial da Previdência Social brasileira (BRASIL, 2003).

Ainda segundo avaliação do grupo técnico assessor, a participação dos sindicalistas no Observatório teve altos e baixos relacionados, em muitas ocasiões, com a dinâmica interna das centrais e do movimento sindical. Por exemplo, todas as centrais sindicais participaram dos seminários e enviaram representantes de sindicatos importantes para os eventos. Alguns representantes das centrais mantiveram compromisso constante com o OST, enquanto outros mantiveram relação mais distante e ocasional. A experiência do OST sugere que, por um lado, há interesse em construir um vínculo contínuo e duradouro com profissionais e técnicos da área de Saúde do Trabalhador, claramente manifestado e demonstrado por várias lideranças sindicais das centrais comprometidas com a saúde do trabalhador. Por outro, não há suficiente apoio nas próprias centrais para que se invista neste esforço. Esta dificuldade parece explicar a participação irregular de algumas Centrais no Observatório.

A maioria dos representantes das centrais compareceu e participou das reuniões de planejamento e seminários, embora não tenham demonstrado participação ativa e mobilizada na colocação de documentos, notícias e links no portal. Esta atitude pode, por um lado, revelar maior interesse em agregar informações às páginas de internet das próprias centrais cujos links figuram no portal do Observatoriost, sem perder a participação política na articulação coletiva das lideranças sindicais interessadas na Saúde do Trabalhador. Por outro lado, pode também sinalizar a expectativa de que apenas os técnicos e os acadêmicos desempenhassem seu papel na seleção e na difusão das informações técnicas e políticas pelo portal. 
A coordenação rotativa do Fórum das Centrais evidenciou também maturidade política para articulação em ambiente no qual existem muitos conflitos de ordem política, cultural e econômica. Quando os conflitos da política sindical se aprofundam entre os próprios representantes dos trabalhadores, a política unificada de saúde tende a assumir aspectos secundários. Essa mesma política unitária pode ou não ser retomada à medida que confluem as demandas dos trabalhadores por políticas públicas que defendam seus serviços de saúde contra a privatização e a redução dos benefícios impostos pelo capital financeiro contra o estado de bem-estar social. (HARVEY, 1989, 2005).

\section{Situação atual do Observatoriost e perspectivas futuras}

A página de internet do Observatoriost dispõe de orçamento inicial para permanecer no ar até abril de 2013. Segundo estatísticas do provedor de serviços de internet, o portal recebeu cerca de 300 visitantes por mês no primeiro semestre de 2012, sendo que $75 \%$ das visitas eram de visitantes que estavam retornando ao site após visitas anteriores.

Ocorreram mais de duzentos pedidos de envio sistemático de aviso de renovação de notícias pelo comunicado automático do tipo podcast e eventuais boletins. A maioria desses pedidos de atualização foi procedente de lideranças sindicais de base e de profissionais de saúde ligados aos Cerests da Renast. Os visitantes da internet visualizaram mensalmente cerca de mil páginas do portal com acesso a notícias, links e documentos do repositório de arquivos em formato PDF.

Os técnicos do grupo editorial do portal foram convidados, durante o período de 2006 a 2012, a participarem de vários seminários e fóruns das centrais participantes em São Paulo, Brasília, Rio de Janeiro, Salvador e Porto Alegre, onde apresentaram a evolução do Observatório e participaram de discussões sobre as políticas de Saúde do Trabalhador de interesse das organizações sindicais que promoveram as reuniões.

As centrais sindicais participantes do Comitê Editorial não definiram sua continuidade além desse período. Este processo não teve desfecho até o momento em que foi redigido este relato de experiência. Espera-se a continuidade do processo de discussão entre as centrais sindicais sobre estratégias de coordenação e de financiamento para além dos recursos iniciais governamentais. A ação sindical unificada não abre espaços para recriminações ou divisionismos antes que tenha sido feito todo esforço pela continuidade do projeto, incluindo novos parceiros na política sindical que está em constante desenvolvimento.

\section{Conclusão}

O Observatóriost obteve, como resultados principais, avanços na unidade política e programática para ação unitária do Movimento Sindical com profissionais da área de Saúde do Trabalhador. Adotaram-se estratégias de difusão de informações relevantes para orientar a luta pelo estabelecimento de políticas públicas de Saúde do Trabalhador. Embora a intenção do projeto fosse construir o Observatório de Saúde do Trabalhador como uma rede, após mais de três anos de experiência concreta, há que se reconhecer que este OST funciona muito mais como uma clearinghouse que como rede. Como clearinghouse, organizou e publicou com sucesso grande número de documentos, artigos, notícias de eventos, vídeos, dentre outros que têm sido utilizados por pesquisadores, sindicalistas e profissionais da área de Saúde do Trabalhador.

Houve dificuldades na consolidação financeira da rede e do portal que poderão ser superadas com o desenvolvimento dos mecanismos de editoração do portal e de reforço para a rede científica e sindical nos setores saúde e ambiente. A adoção de secretariado geral rotativo e a gestão por consenso constituem estratégias de superação de impasses que podem dar base duradoura para o crescimento tanto do Fórum das Centrais, quanto do portal do Observatoriost no seu papel de criar consensos e políticas de unidade.

A superação das insuficiências de articulação e financiamento poderá ser atingida com reforço aos mecanismos de atuação consensual, conseguindo recursos humanos e financeiros para o trabalho técnico-científico de buscar informação, ancorar a página de internet e garantir mecanismos de disseminação de livre acesso para qualquer trabalhador ou estudioso interessado. A integração política dos representantes das centrais sindicais brasileiras com as instâncias participativas abertas pelos Ministérios das Áreas Sociais, como Saúde, Previdência, Trabalho, Educação, entre outras, poderão reforçar o papel técnico-científico de subsidiar o controle social e o estabelecimento de novas políticas públicas para o setor.

Outra decorrência importante é criar mecanismos de formação de novos pesquisadores, estudiosos e técnicos que conheçam a dura realidade enfrentada pelos trabalhadores, participando junto com eles na busca de alternativas para modificá-la e abrindo espaços nos órgãos e serviços públicos, na academia e em outras instituições de formação e pesquisa que contribuam para a construção e a consolidação de frentes de resistência ao processo crescente de precarização do trabalho, que traz graves consequências para a saúde e a segurança no trabalho 


\section{Contribuições de autoria}

Siqueira, C. E.: Contribuição principal no projeto e no delineamento, no levantamento de dados ou na sua análise e interpretação; elaboração do manuscrito ou contribuição importante na sua revisão crítica; aprovação final da versão a ser publicada. Pedra, F.; Corrêa Filho, H. R.; Castro, H. A. de: Contribuição substancial no projeto e no delineamento, no levantamento de dados ou na sua análise e interpretação; elaboração do manuscrito ou contribuição importante na sua revisão crítica; aprovação final da versão a ser publicada. Maeno, M.: Contribuição no levantamento de dados, na análise e na interpretação; elaboração do manuscrito ou contribuição importante na sua revisão crítica; aprovação final da versão a ser publicada.

\section{Agradecimentos}

Os autores agradecem às Centrais Sindicais Brasileiras o apoio institucional e político para articular estudos e pesquisas acadêmicos com a realidade do mundo do trabalho. Esse agradecimento é dirigido às centrais que aceitaram desencadear o processo de criação e sustentação do Observatório de Saúde do Trabalhador. Os nomes e os portais das centrais podem ser vistos e acessados como links diretos por meio da página do Observatoriost.

\section{Referências}

BOITO, A.; GALVÃO, A.; MARCELINO, P. Brasil: o movimento sindical e popular na década de 2000. OSAL - Observatorio Social de América Latina, Buenos Aires, ano 10, n. 26, p. 35-55, out 2009. Disponível em: <http://bibliotecavirtual.clacso.org.ar/ar/libros/ osal/osal26/05boito.pdf>. Acesso em: 25 jan. 2012.

BRASIL. Lei Federal no 10.666, de 08 maio 2003. Dispõe sobre a concessão da aposentadoria especial ao cooperado de cooperativa de trabalho ou de produção e dá outras providências, Artigo 10, Fator Acidentário de Prevenção - FAP. Diario Oficial [da] República Federativa do Brasil, Brasília, DF, de 08 de maio de 2003. Disponível em: < http://www.planalto. gov.br/ccivil_03/leis/2003/L10.666.htm>. Acesso em: 9 maio 2003.

. Ministério da Previdência Social. Listas de morbidade e agentes nocivos do trabalho. Regulamento da Previdência Social. Anexo II do Decreto no 6.042, de 12 de fevereiro de 2007. Diário Oficial [da] República Federativa do Brasil, de 12 de fevereiro de 2007, v. 6042. Disponível em: <http:// www010.dataprev.gov.br/sislex/paginas/23/1999/ ANx3048.htm > . Acesso em: 15 de maio de 2013.

. Rede Nacional de Atenção Integral à Saúde do

Trabalhador: manual de gestão e gerenciamento. São Paulo: Renast, 2006. Disponível em:<http://portal. saude.gov.br/portal/arquivos/pdf/ManualRenast07. pdf>. Acesso em: 17 maio 2013.

CONFEDERAÇÃO NACIONAL DA INDÚSTRIA. Liminar da Justiça impede aplicação do FAP, Jornal Valor Econômico de 17 de dezembro de 2009, Seção Legislação \& Tributos, p. E2. In: CLIPPING do Sistema Indústria, CNI-SESI-SENAI-IEL, 2009. Disponível em: <http://www.ntu.org.br/novosite/arquivos/Noticia Valor_Economico.PDF $>$. Acesso em:16 maio 2013.

\section{CONSELHO NACIONAL DE SECRETÁRIOS}

MUNCIPAIS DE SAÚDE. Participação social no SUS:

o olhar da gestão municipal. Manual para gestores municipais. [S.I.]: Conselho Nacional de Secretários Muncipais de Saúde, 2011. Disponível em:<http://www. cosemsms.org.br/publicacoes/cartilha_participacao_ social_setembro.pdf > . Acesso em: 23 maio 2013.

DIAS, E. C.; HOEFEL, M. D. G. L. O desafio de implementar as ações de saúde do trabalhador no SUS: a estratégia da Renast. Ciência \& Saúde Coletiva, Rio de Janeiro, v. 10, n. 4, p. 817-827, 2005.

HARVEY, D. The condition of postmodernity. New York: Oxford University Press \& Blackwell, 1989.

. A brief history of neoliberalism. New York: Oxford University Press, 2005.

LACAZ, F. A. D. C. Reforma sanitária e saúde do trabalhador. Saúde e Sociedade, São Paulo, v. 3, n. 1, p. 41-59, 1994.

NEXO TÉCNICO EPIDEMIOLÓGICO E FATOR ACIDENTÁRIO DE PREVENÇÃO, 2009, São Paulo. Arquivos... São Paulo: Fundacentro, 2009. Disponível em: <http://www.fundacentro.gov.br/dominios/CTN/ indexEvento.asp? $\mathrm{D}=\mathrm{CTN} \& \mathrm{PAGINA}=\mathrm{CONTEUDOEVE}$ NTO\& $? \mathrm{D}=\mathrm{CTN} \& \mathrm{C}=2174 \&$ menuAberto $=345>$. Acesso em:16 maio 2013.

OLIVEIRA, P. R. A. D. Nexo Técnico Epidemiológico Previdenciário - NTEp - Fator Acidentário de Prevenção - FAP: um novo olhar sobre a saúde do trabalhador. 2. ed. São Paulo: LTR, 2010.

PIMENTA, A. L.; CAPISTRANO-FILHO, D. Saúde do trabalhador. São Paulo: Hucitec, 1988.

PINA, J. A.; CASTRO, H. A.; ANDREAZZI, M. F. A. Sindicalismo, SUS e planos de saúde. Ciência \& Saúde Coletiva, Rio de Janeiro, v. 11, n. 3, p. 837-846, 2006. 
SIQUEIRA, C. E.; CARVALHO, F. The observatory of the Americas as a network in environmental and worker health in the Americas. Ciência \& Saúde Coletiva, Rio de Janeiro, v. 8, n. 4, p. 897-902, 2003. SIQUEIRA, C. E.; CASTRO, H.; ARAUJO, T. M. A globalização dos movimentos sociais: resposta social à globalização corporativa neoliberal. Ciência $\&$ Saúde Coletiva, Rio de Janeiro, v. 8, n. 4, p. 847-858, 2003.

SOARES, V. D. A. Os trabalhadores e a questão da saúde: 1890-1920. 1985. 196 f. Dissertação (Mestrado em Saúde Pública)-Escola Nacional de Saúde Pública Sérgio Arouca, Fundação Oswaldo Cruz, Rio de Janeiro, 1985. 